\title{
Monthly variation in masses, metals and endotoxin content as well as pro-inflammatory response of airborne particles collected by TEOM monitors
}

\author{
Stefan A. Ljunggren ${ }^{1}$ (D) - Ali Reza Nosratabadi ${ }^{1}$ - Pål Graff ${ }^{2} \cdot$ Helen Karlsson ${ }^{1}$
}

Received: 27 June 2019 / Accepted: 4 November 2019/Published online: 16 November 2019

(C) The Author(s) 2019

\begin{abstract}
Particle exposure has been linked to an increased incidence of cardiovascular disease. Furthermore, particle exposure has been shown to have a chronic inhibitory effect on lung development in young people and may result in increased respiratory problems in adults or children with respiratory-related diseases. In today's urban environments, particle levels are mainly monitored gravimetrically; however, other factors such as particle size, shape and surface reactivity have recently been noted as highly important in relation to possible health outcomes. Here, particles from TEOM monitor filters placed in three different cities were studied. The purpose of the study was to investigate whether there are variations in particle masses, cadmium and lead contents, as well as endotoxin levels between locations and time points over the year and if this can be correlated to the particles ability to induce a pro-inflammatory response in vitro. Results showed that it is possible to detect variations at different locations and at different time points over the year and that cadmium, lead and endotoxin levels did not coincide with the increased total particle masses while endotoxin levels coincided with pro-inflammatory responses in vitro. The present study shows that filter analysis is a useful complement to gravimetric or particle-counting measurements in studies of particle-related health effects and will give useful information regarding future air quality measurements.
\end{abstract}

Keywords Particles $\cdot$ PM10 $\cdot$ Exposure $\cdot$ TEOM $\cdot$ Metals $\cdot$ Endotoxins $\cdot$ Pro-inflammatory response

\section{Introduction}

A number of studies have shown that exposure to air pollution increases the risk of mortality in lung as well as cardiovascular diseases (Pope et al. 2018; Stockfelt et al. 2017; Fiordelisi et al. 2017). The term air pollution, however, includes a variety of substances. In Sweden's air quality regulation (SFS 2010:477), air pollution includes the presence and air content of nitrogen dioxide, sulphur dioxide, particles (PM10 and PM 2.5 ), benzene, carbon monoxide, ozone, polyaromatic hydrocarbons (with benzo (a) pyrene as indicator) and the metals

Stefan A. Ljunggren and Ali Reza Nosratabadi contributed equally to this work.

Stefan A. Ljunggren

stefan.ljunggren@liu.se

1 Occupational and Environmental Medicine Center, and Department of Clinical and Experimental Medicine, Linköping University, Linköping, Sweden

2 National Institute of Occupational Health, Oslo, Norway arsenic, lead, nickel and cadmium. In connection with the introduction of environmental quality standards, particles have been recognised as an increasing air pollution problem (IVL Swedish Environmental Research Institute 2016). Particle exposure, in addition to the increased incidence of cardiovascular disease, has been shown to have a chronic inhibitory effect on lung development in young people between 10 and 18 years of age and may result in increased respiratory problems in children with respiratory-related diseases (Gauderman et al. 2004; O'Connor et al. 2008).

In today's urban environments, particle levels are mainly monitored gravimetrically, which means that the particle contents are based on mass. However, other factors such as particle size, shape and surface reactivity have recently been noted as highly important in relation to possible health outcomes (Golokhvast et al. 2015; Steenhof et al. 2011; Ristovski et al. 2012). These factors are likely to be of interest since small particles may end up deeper in the lungs and have a larger combined surface area compared with large particles. Variation in particle properties have also been shown to be of importance for the degree of toxicity and inflammationinducing potential which has been demonstrated for wear 
particles from tires and road surfaces (Araujo 2010; Lindbom et al. 2006, 2007; Karlsson et al. 2011; Gustafsson et al. 2008; Boogaard et al. 2012).

This study is based on a previous study, where the possibility of using filters from existing TEOM stations for further characterisation of particle properties was explored (Nosratabadi et al. 2019). The earlier study showed that the particle masses peaked in March/April while the oxidative capacity of the particles was at its highest early in the spring and the content of endotoxins and the pro-inflammatory response were highest in late summer. This indicates that the source and composition of the particles are different over the year and may pose different health risks (Nosratabadi et al. 2019). In the present study, a more in-depth analysis of TEOM filters collected monthly in three cities in the southeast part of Sweden are presented. The main purpose of the study was to investigate whether there are variations in particle masses, metal contents $(\mathrm{Cd}, \mathrm{Pb})$ and endotoxins between locations and time points over the year and if this can be correlated to the particles ability to induce pro-inflammatory response in vitro.

\section{Methods}

\section{Particulate matter (PM10) in air}

Particulate matter with a size less than $10 \mu \mathrm{m}$ (PM10) were collected on filters by TEOM monitors. Filters were collected at four sites located in three different cities in the southern part of Sweden during 1 year (September 2014-August 2015). In detail, particles have been collected from two different TEOM stations placed in two different streets (street 1 "Kungsgatan" and street 2 "Promenaden") in a city connected to the Baltic Sea via a bay, (city 1, Norrköping, 96,500 inhabitants), from one TEOM station placed in an inland city, (city 2, Linköping, 100,000 inhabitants) and from one TEOM station placed in a smaller city located in direct connection to the Baltic Sea (city 3, Kalmar, 36,500 inhabitants). From street 2 in city 1, a similar filter collection has previously been done for one year (September 2009-August 2010).

Mean monthly values for the ambient particle concentrations were calculated based on data from the TEOM monitors that had been sent to a national database handled by the Swedish Meteorological and Hydrological Institute (SMHI). Information regarding temperatures in the three cities was collected from open data provided by SMHI.

\section{Extraction of particles from TEOM filters}

The TEOM monitors and the collection of particles from the TEOM filter are described in detail in a previous study (Nosratabadi et al. 2019). In short, TEOM monitors, which are used worldwide, measure the ambient concentration of particles (PM10 or PM2.5) in real time. TEOM monitors are gravimetric instruments that draws ambient air through a filter at a constant flow rate $(3 \mathrm{~L} / \mathrm{min})$, while continuously weighing the filter, measuring ambient particulate mass concentrations (Patashnick and Rupprecht 1991). Replacement of the TEOM filters was carried out according to instructions every month for 1 year (September 2014-August 2015) by personnel from the respective municipality. A total of 48 filters were collected from the four TEOM stations. After each replacement, the TEOM filters were sent to the Occupational and Environmental Medicine laboratory at the Linköping University Hospital. Upon arrival at the laboratory, each sample was recorded and the tube with filters was then placed in a low temperature freeze $\left(-70^{\circ} \mathrm{C}\right)$ while awaiting weighing, particle extraction and analysis.

To determine the mass of the particles, each filter was weighed with a precision microbalance with a reading precision of $10 \mu \mathrm{g}$ (Sartorius Micro MC5 P). Before the weighing, each filter was stored for $48 \mathrm{~h}$ in a room with a controlled temperature and humidity $\left(24{ }^{\circ} \mathrm{C}\right.$ and $\left.55 \% \pm 2 \%\right)$. At the same time, two unexposed control filters were also weighed. The weighing was performed twice, before and after the extraction to calculate the mass of particles released during the extraction.

After the first weighing, each filter was placed in a sterile 50-mL Falcon tube and $2 \mathrm{~mL}$ of endotoxin-free water was added (Braun Malsungen AG, Germany). To extract the particles from the filter, an ultrasonic probe was used for $5 \times 10 \mathrm{~s}$ per filter (MSE Soniprep 150 Ultrasonic Disintegrator, Heathfield, UK). The suspension with extracted particle was allocated in fractions of $500 \mu \mathrm{L}$ and frozen at $-30{ }^{\circ} \mathrm{C}$ pending analysis.

\section{Metal analysis}

For determination of relative amounts of lead and cadmium in the samples, an atomic absorption spectrophotometry (ContrAA 700 with graphite furnace, Analytik Jena AG, Jena, Germany) was used. The frozen samples were thawed at room temperature and transferred to a Teflon tube. The Teflon tubes were placed in a heating cabinet $\left(50{ }^{\circ} \mathrm{C}\right)$ for $15 \mathrm{~h}$ until dried, then $300 \mu \mathrm{L}$ of nitric acid and $100 \mu \mathrm{L}$ of water were added to each tube. The Teflon tubes were then incubated in a heating cabinet $\left(80^{\circ} \mathrm{C}\right)$ overnight for $16 \mathrm{~h}$. After incubation, $600 \mu \mathrm{L}$ of deionised water was added to each tube and mixed for $5 \mathrm{~s}$ using a vortex before the analysis.

\section{Endotoxins}

The endotoxin content on each filter was analysed using a specific Limulus assay (Pierce ${ }^{\mathrm{TM}}$ LAL Chromogenic endotoxin quantitation kit, Thermo Fisher Scientific, Waltham, MA, 
USA) according to the manufacturer's instructions. Briefly, $10 \mu \mathrm{g}$ of particles in suspension and standard was added to wells of a 96-well plate and incubated for $5 \mathrm{~min}$ at $37^{\circ} \mathrm{C}$. To this was added $50 \mu \mathrm{L}$ of limulus amebocyte lysate (LAL) and the plate was incubated for $10 \mathrm{~min}$ before a chromogenic substrate was added followed by 6 min incubation at $37^{\circ} \mathrm{C}$. The endotoxin levels were determined using a spectrophotometer measuring at $405 \mathrm{~nm}$ (FLUOstar, BMG Labtech, Ortenburg, Germany).

\section{Pro-inflammatory response}

The potential for the collected particles to induce a proinflammatory response was measured by incubating plasma from a healthy donor with particles and then measuring the formed content of IL- $1 \beta$ with a commercial ELISA kit (Invitrogen, Carlsbad, CA, USA) according to the manufacturer's instructions. Briefly, $100 \mu \mathrm{L}$ of whole blood was mixed with $20 \mu \mathrm{g}$ of extracted particles and incubated for $18 \mathrm{~h}$ at $37^{\circ} \mathrm{C}$. The following day, the sample was centrifuged at $14,000 \mathrm{~g}$ for $5 \mathrm{~min}$. Residual supernatants (blood plasma) were analysed with ELISA kits in which antibodies bound in a 96-well plate bind to IL-1 $\beta$ and, via an enzymatic method, dye is read at $450 \mathrm{~nm}$ (FLUOstar, BMG, Germany).

\section{Statistics}

Differences between the cities were investigated using Friedman test with Dunns multiple comparison post-test. Differences between the two measured periods at the same location were analysed by Wilcoxon matched pairs test. A $p$ value below 0.05 was considered significant.

To investigate the different measures variability over the year, a multivariate model (OPLS-DA) was created using SIMCA 15.

\section{Results}

\section{Comparison of the three cities}

Particle levels (PM10) in air were calculated gravimetrically using TEOM stations and are reported as monthly mean values in Fig. 1a. These values were calculated from data sent from the TEOM monitors and collected in a national database at the Swedish Meteorological and Hydrological Institute (SMHI). There were significantly higher particle levels in city 1 location 1 and city 2 compared with city 3 in pair-wise monthly comparisons $(p<0.05)$.

The average monthly temperature differed between the cities where city 2 ,which is located inland, showed significantly lower temperature than both locations in city $1(p<0,01)$ and city 3 ( $p<0.001$, Fig. $1 b$ ). These differences were however very small in absolute numbers as can be seen in Fig. 1 b.

Extracted particles from the TEOM filters were analysed for their relative metal content. Cadmium levels were significantly higher in city 3 compared with city 1 location $1(p<0.001)$ as well as city $2(p<0.01$, Fig. $1 c)$. For lead, city 1 location 2 showed significantly higher levels compared with both city 1 location $1(p<0.05)$ and city $2(p<0.01$, Fig. 1d). Lead levels in city 3 showed a clear increase compared with city 2 and city 1 location 1 but this was not statistical significant.

Endotoxin tests and pro-inflammatory responses via IL- $1 \beta$ analysis showed a similar trend comparing all locations over the year but no significant differences between the cities was found (Fig. 1e, f). However, a positive correlation could be seen between the levels of endotoxin and IL- $1 \beta$ when comparing all measures (Spearman correlation, $R=0.5, p<0.001$ ).

\section{Co-variation over the year}

The co-variation of the investigated variables over the year was investigated using a multivariate model with OPLS-DA. This model aims at separating a set of $y$-variables (in this case, the different months) using a set of $x$-variables (in this case, the measures of particle mass, temperature, metal levels, endotoxin content and IL-1 $\beta$ ) that allows for detecting underlying co-variation. This co-variation can be seen as a clustering of investigated $y$-and $x$-variables in a two-dimensional plane in a so-called loading plot of the investigated factors. As can be seen in Fig. 2, the endotoxin content and proinflammatory response (IL-1 $\beta$ ) showed the highest levels during the summer months (May to August), illustrated as a clustering to the right in the image. The PM10 particle concentrations were highest in March, while both the lead and cadmium concentrations on the TEOM filters were higher during the winter months (especially November, seen as clustering to the bottom left).

\section{Time trend of particles and metal content in city 1}

At location 2 in city 1 , data was available from 5 years prior to the current study, which allowed a comparison of time trends at this location. Particle concentrations were in general lower 2014-2015 compared with 2009-2010, and the highest peaks occurred in April 2010 and in March 2015 (Fig. 3a). The delay in 2010 may be explained by that the temperature was in general higher during 2014-2015 (Fig. 3b). When looking at the metal content of the collected particles, cadmium showed a significant and lead a close-to-significant decrease years 2014-2015 compared with 2009-2010 (Fig. 3c, d). Interestingly, the highest peaks of the metals occurred in November to February in 2009-2010, a period when the total particle masses collected by the TEOM station were relatively low. 

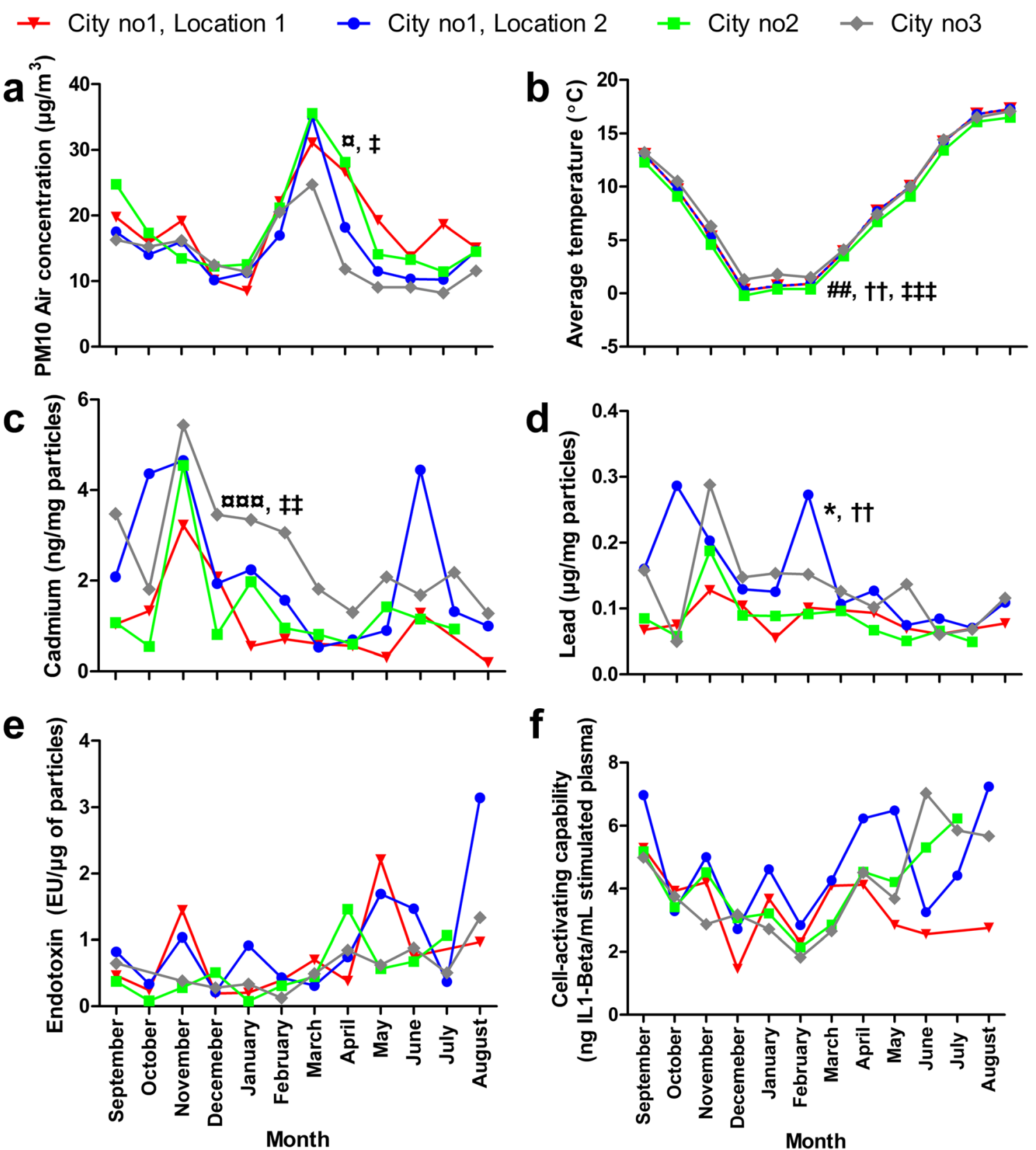

Fig. 1 Comparison of monthly values at four different sites in three different cities. a PM10 particle concentrations $\left(\mu \mathrm{g} / \mathrm{m}^{3}\right)$ in air as reported by the TEOM stations. b Average temperatures. c Concentration of cadmium in the collected dust from the TEOM stations. d Concentration of lead in the collected dust from the TEOM stations. e Endotoxin levels in the collected dust from the TEOM stations.

\section{Discussion}

\section{Particles in air}

Particulate matter (PM10) masses in air were calculated during the period September 2014-August 2015, based on information from TEOM stations located in three different cities in Sweden (Fig. 1a). The highest monthly averages for PM10 in the four locations coincided in March 2015. The two
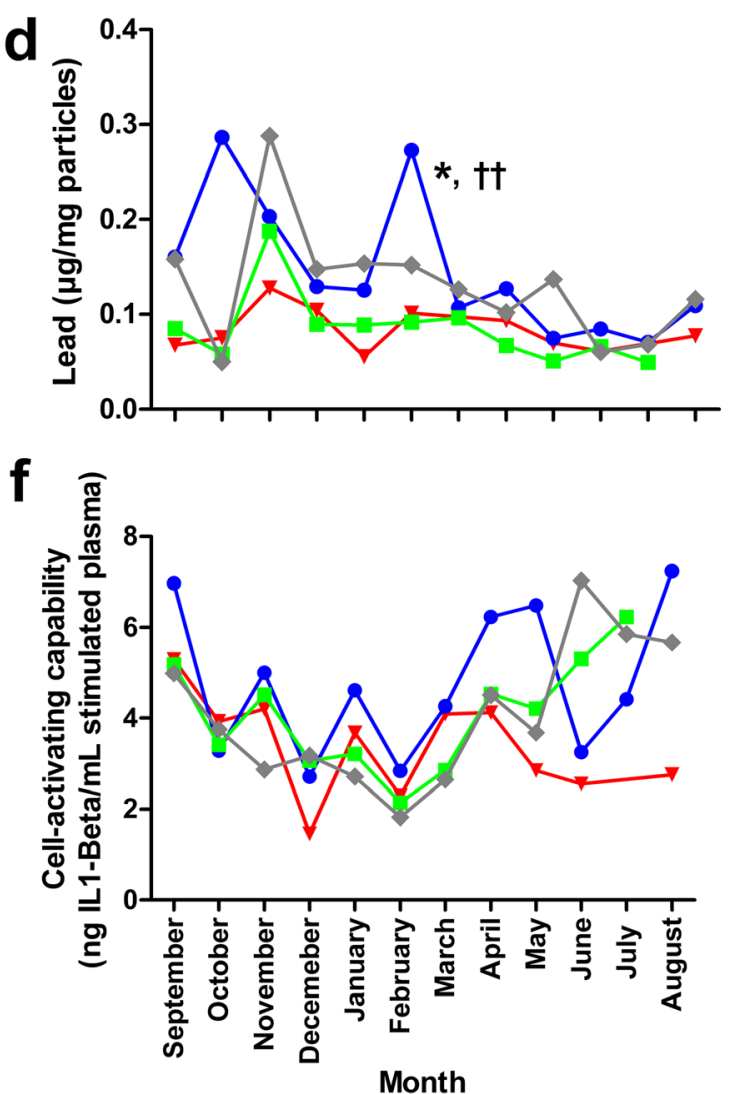

f Pro-inflammatory response measured by the amount of IL- $1 \beta$ produced after incubation of human plasma over night with collected particles. ${ }^{*} p<$ 0.05 city 1 location 1 vs location $2,{ }^{\# \#} p<0.01$ city 1 location 1 vs city 2 , a poos $p<0.05 / 0.001$ city 1 location 1 vs city $3,{ }^{\dagger} p<0.01$ city 1 location 2

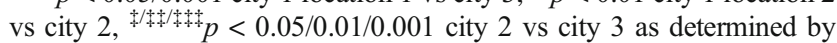
Friedman's test with Dunn's multiple comparison post-test

measuring locations in city 1 (Norrköping) showed the highest monthly averages that approached $40 \mu \mathrm{g} / \mathrm{m}^{3}$, while the monthly average in city 2 (Linköping) reached just over 30 $\mu \mathrm{g} / \mathrm{m}^{3}$ followed by city 3 (Kalmar) with about $25 \mu \mathrm{g} / \mathrm{m}^{3}$. High levels of airborne particles in the spring have for a long time been considered a problem in Nordic countries (Nosratabadi et al. 2019). However, the timing of when the highest levels occur during the spring may vary slightly from year to year depending on the weather as can be seen in Fig. 3a, b. The 


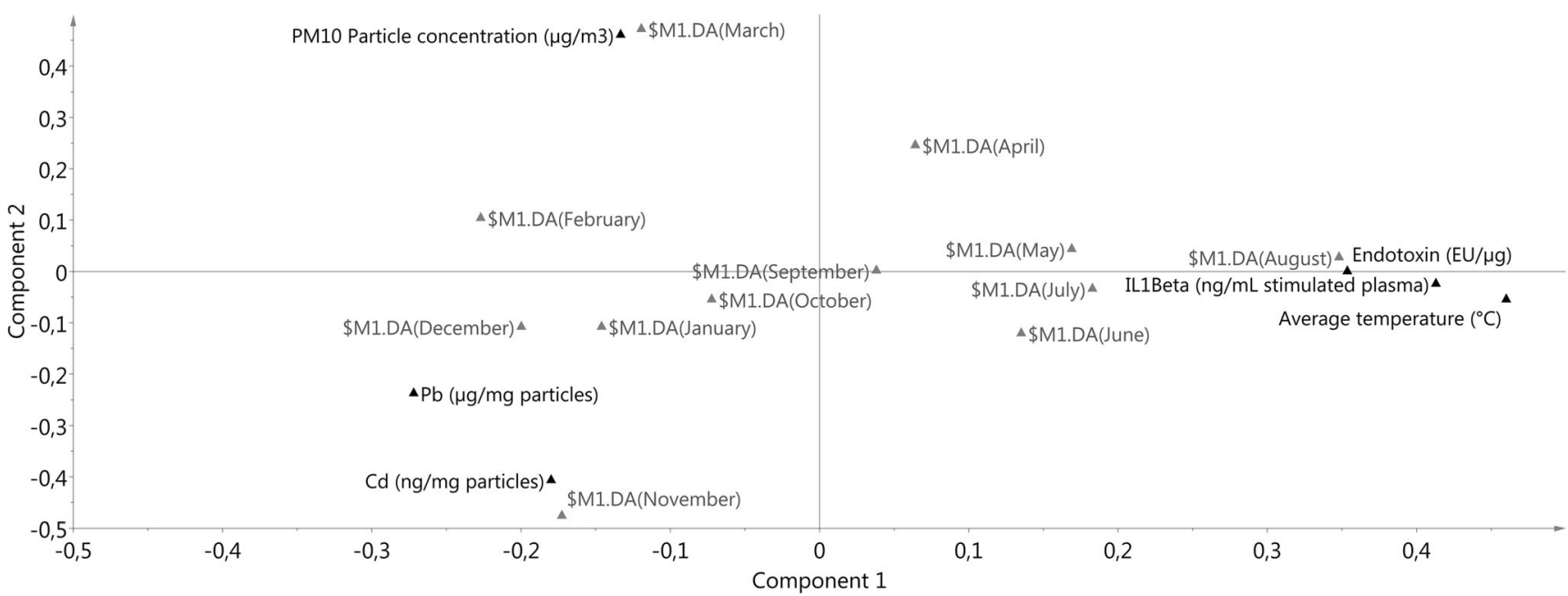

Fig. 2 Loading plot of the multivariate modelling of the investigated variables (black triangles) at the four TEOM stations and their variability during the year (months in grey triangles). Variables and months clustering indicate an underlying pattern of increased level of

high particle levels in the spring are to a high extent resulting from wear particles that are formed during friction between studded tires and roadway during the winter. When spring the variable during that month. The $x$-axis of the plot is the so-called predictive component that explains most of the variability between months while the $y$-axis is the orthogonal component indicating further variability.

arrives and the road becomes dry, generated particles are free to become airborne and thereby inhaled (Gustafsson et al. 2008). PM10 in air is a rough measure of possible particle-

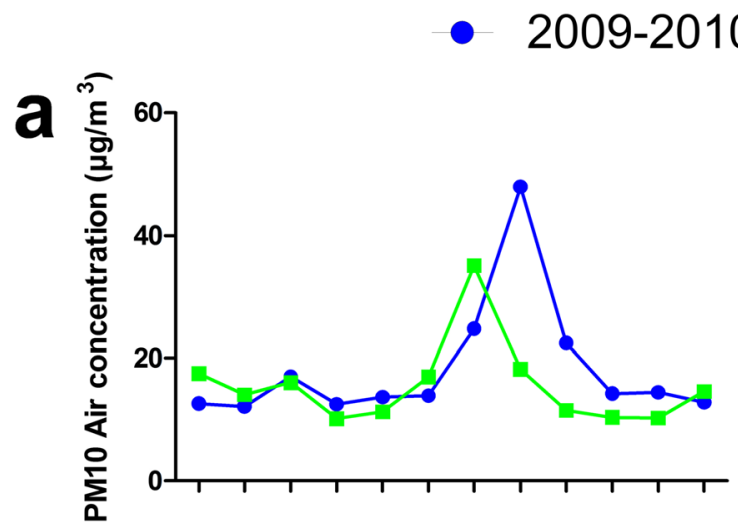

\section{4-2015}

b
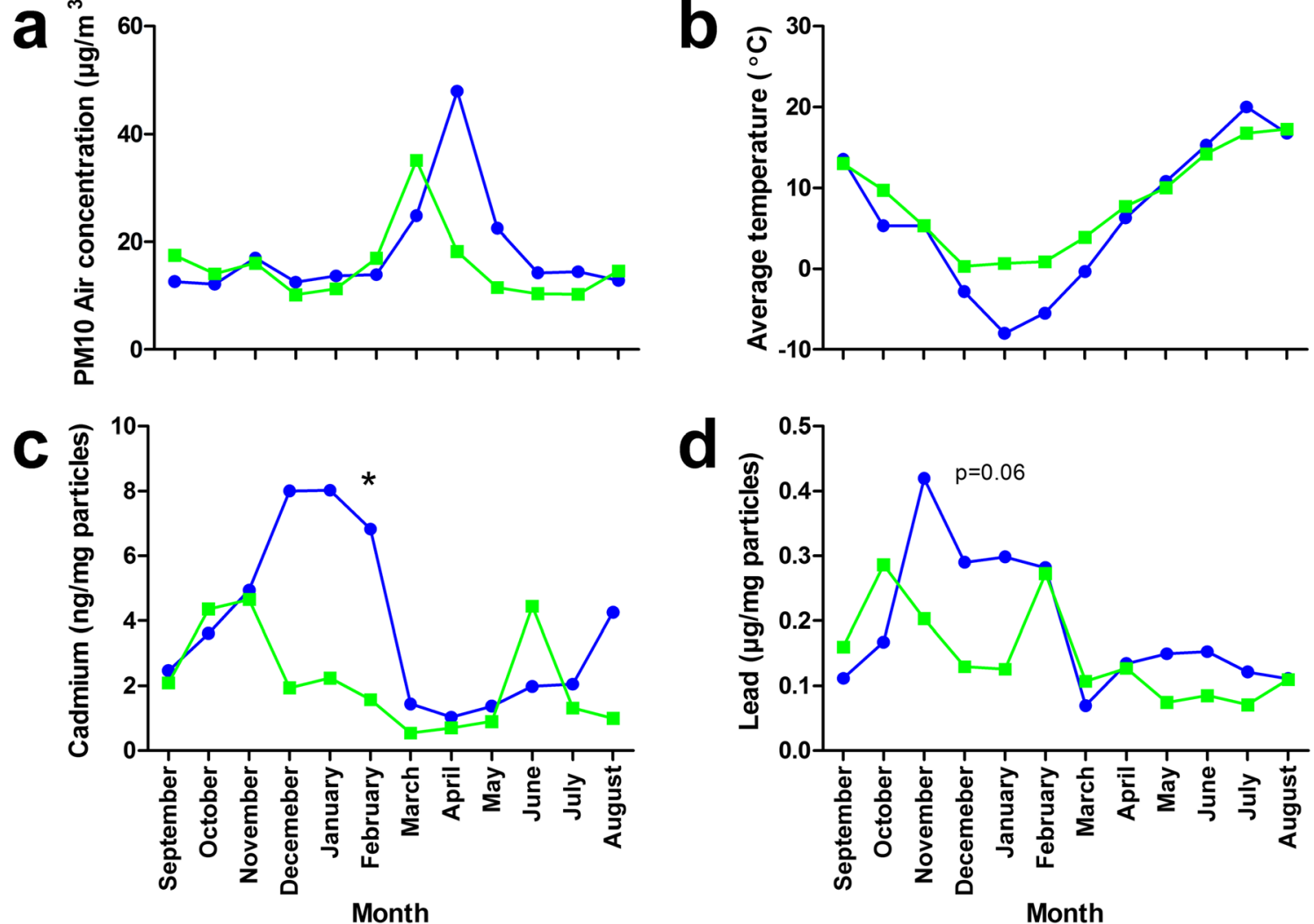

Fig. 3 Comparison of PM10 particle concentrations, temperature, cadmium and lead content years 2009-2010 and 2014-2015 in city 1 at location 2. a Monthly mean values of particle concentration $\left(\mu \mathrm{g} / \mathrm{m}^{3}\right)$ in air as reported by the TEOM stations. b Average temperature as collected

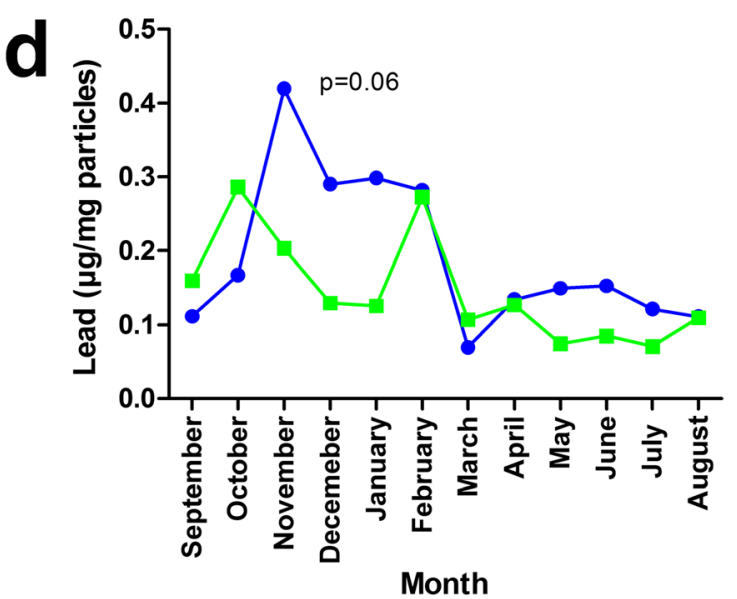

from open data hosted by the Swedish Meteorological and Hydrological Institute (SMHI). c Concentration of cadmium in the collected dust from the TEOM stations. $\mathbf{d}$ Concentration of lead in the collected dust from the TEOM stations. ${ }^{*} p<0.05$ 
related health effects since recent research has shown that smaller combustion particles may be more relevant to study (Xing et al. 2016) and that it is also of great importance what element the particles consist of and what they carry on their surface (Ali et al. 2018). The reason why monthly averages are used in the present study is that these values can be related to the monthly filter changes and thus the particle masses. Unfortunately, monthly average values cannot be directly related to the environmental quality standard (EQS), but they can reflect measures taken by authorities responsible for air quality in the street environments. None of the cities participating in this study exceeded EQS during the study period 2014-2015 but Fig. 3 a reflects the lowering of airborne particles in city 1 location 2, comparing the two periods 20092010 with 2014-2015. This lowering is probably due to performed action plans to reduce particles after previous overruns of EQS in city 1 in years 2005 and 2009.

\section{Metal content of collected particles}

Filters from all locations showed a similar trend in cadmium and lead levels over the year (Fig. 1c, d). Interestingly, elevated cadmium level did not coincide with monthly mean values for PM10 levels in air and was surprisingly higher in the smaller city 3 than in the larger city 1 and city 2 . The origin of this cadmium has to be further studied but according to the Swedish Environmental Health Report 2017 (administered by the Public Health Agency of Sweden), participants in this particular region report that they are disturbed by smoke from private wood burning. Furthermore, the city also has metallurgical industry as well as shipping activities that may contribute to cadmium levels. Lead on the other hand showed a significant increase in city 1 location 2 compared with city 1 location 1 as well as to city 2 . The differences found within city 1 may depend on that location 2 has more traffic $(58 \%$ more as analysed by the municipality) and that it is located closer to a larger industrial area as well as shipping activities. The latter is interesting in the light of the fact that city 3 that had a clear but non-significant increase of lead compared with city 1 location 1 and city 2 also has shipping activities that may contribute to the detected levels on the TEOM filters.

However, in city 1 location 2, the levels of cadmium years 2014-2015 were significantly reduced compared with years 2009-2010 (Fig. 3c, $p<0.05$ ). Lead showed a similar trend although not significant (Fig. 3d). Lead and cadmium are included in the Swedish air quality regulation (SFS 2010: 477). The regulation states, in order to protect human health, the annual mean levels of cadmium should not exceed $5 \mathrm{ng} / \mathrm{m}^{3}$. In addition, lead should not exceed an annual mean value of $0.5 \mu \mathrm{g} / \mathrm{m}^{3}$. These units are not directly comparable with the units in the present study, but it can be clearly seen in Fig. 3 that both lead and cadmium content per particle dust mass have decreased comparing years 2014-2015 with years
2009-2010. Metal measurements in moss in this area during the period 1985-2015 support our findings regarding lead and cadmium, showing a decreasing trend (IVL Swedish Environmental Research Institute 2016).

\section{Endotoxins}

Endotoxins are bacterial components often found in our immediate environment and when we are exposed, the immune system reacts strongly to be prepared for a possible infection (Levels et al. 2011). The internalisation of endotoxins in macrophages and endothelial cells results in local production of inflammatory cytokines with subsequent migration of inflammatory cells into the lung and the penetration of cytokines into the blood (Rylander 2002).

Endotoxin exposure is a well-known health risk for, among other things, personnel handling organic waste or cutting fluids as well as agricultural workers. Chronic inhalation exposure has been linked to health effects including cough, shortness of breath, fever, headache and inflammation in various occupational settings (Liebers et al. 2008). Endotoxins can adhere to the surface of particles and accompany them into the lungs and the endotoxins may result in more pronounced immunological reactions than the particles themselves. It is thus of interest to know if there are endotoxins extracted with the particles from the TEOM filters and if the levels vary with time points or locations.

The highest peaks of endotoxins at the different locations were obtained late spring/summer, similar to what has been described before (Carty et al. 2003). During the summer, the particle levels are relatively low, indicating the importance of analysing also what the particles carry on their surface. These results confirm the previous study (Nosratabadi et al. 2019) and are realistic since at this time of the year, when it is warm and humid, conditions are particularly beneficial for bacterial growth (Fig. 1e).

\section{Pro-inflammatory response}

As a marker for pro-inflammatory response, the cytokine interleukin-1 $\beta$ (IL-1 $\beta$ ) was analysed in the present study. To mimic an in vitro fever reaction, the abundance of IL- $1 \beta$ was measured in blood samples exposed to particle solutions from the different sites and time points. An increase in proinflammatory response could be seen during summer and early autumn in all cities, which largely coincided with the time points when the endotoxin levels were elevated in the collected particles (Fig. 1f).

These results indicate that it is important to know what the particles may carry on their surface and that it might be of interest to evaluate endotoxin occurrence in connection with particle content analysis in the future. 


\section{Limitations}

Each TEOM monitor contains one filter that for this study was collected monthly for subsequent analysis. Thereby, only one filter per month has been available from each location. Exact instructions on how the filter change should be performed were distributed, but it cannot be ruled out that filters may have been contaminated in connection with handling.

No morphological characterisation was performed on the collected particles; thus, nothing can be concluded regarding location or seasonal variations in particle size or shape. The mass-based measurement methods did not allow analysis of nanoparticles and therefore, nothing can be said about their presence. In addition, the methods were not suitable for analysing hydrophobic substances such as polycyclic aromatic hydrocarbons (PAH), which would have been highly relevant.

The method used for digestion in this paper will not result in a total digestion of the silicates which might be present in the ambient air. The metal content might therefore be underestimated. However, for the metals presented in the present paper, previous studies have shown that a milder digestion is sufficient (Tursic et al. 2008).

\section{Future perspectives}

Measuring PM10 levels, which already show a decreasing trend in Sweden, is probably not an optimal tool for the future when assessing possible health outcomes. There are also indications on that the development in the automobile industry produces an increased amount of small combustion particles (Liu et al. 2013). Furthermore, there are reports showing increased addition of nanoparticles (e.g. Ce nanoparticles) in certain propellants (Erdakos et al. 2014) that may contribute to an increased risk of high nanoparticle levels in street spaces in the future. Studies of the smaller airborne particles that can move deeper into the lungs and that are able to carry a larger amount of substances on their surface probably give a better picture of possible health risks. In the future, increased measurements of PM2.5 should be considered or the use of particle-counting instruments equipped with a filter for particle surface component analyses.

\section{Conclusion}

The present study of PM10 particles collected on filters, as complement to particle mass calculation, confirms that improved knowledge regarding possible health effects from particle exposure is needed. By analysing filters from TEOM stations, we show that it is possible to detect variations at different locations and at different time points over the year.
Interestingly, cadmium, lead and endotoxin levels did not coincide with the total particle masses while endotoxin levels coincided with inflammatory responses in vitro.

Acknowledgements Thanks to the Research Council of Southeast Sweden, Region Östergötland, Linköping municipality, Norrköping municipality, Kalmar municipality (especially Marie Jönsson for the help with the installation and maintenance of the rented TEOM instrument), E.ON (Kalmar) and Östergötland Air Quality Management Association, which through practical initiatives and financial support contributed to the study.

Funding Information Open access funding provided by Linköping University.

\section{Compliance with ethical standards}

Conflict of interest The authors declare that they have no conflict of interest.

Open Access This article is distributed under the terms of the Creative Commons Attribution 4.0 International License (http:// creativecommons.org/licenses/by/4.0/), which permits unrestricted use, distribution, and reproduction in any medium, provided you give appropriate credit to the original author(s) and the source, provide a link to the Creative Commons license, and indicate if changes were made.

\section{References}

Ali MU, Liu G, Yousaf B, Ullah H, Abbas Q, Munir MAM (2018) A systematic review on global pollution status of particulate matterassociated potential toxic elements and health perspectives in urban environment. Environ Geochem Health:1-32. https://doi.org/10. 1007/s10653-018-0203-Z

Araujo J (2010) Particulate air pollution, systemic oxidative stress, inflammation, and atherosclerosis Air Qual Atmos. Health 4:79-93. https://doi.org/10.1007/s11869-010-0101-8

Boogaard H, Janssen NA, Fischer PH, Kos GP, Weijers EP, Cassee FR, van der Zee SC, de Hartog JJ, Brunekreef B, Hoek G (2012) Contrasts in oxidative potential and other particulate matter characteristics collected near major streets and background locations. Environ Health Perspect 120:185-191. https://oi.org/10.1289/ ehp. 1103667

Carty CL, Gehring U, Cyrys J, Bischof W, Heinrich J (2003) Seasonal variability of endotoxin in ambient fine particulate matter. J Environ Monit 5:953-958. https://doi.org/10.1039/B308488D

Erdakos GB, Bhave PV, Pouliot GA, Simon H, Mathur R (2014) Predicting the effects of nanoscale cerium additives in diesel fuel on regional-scale air quality. Environ Sci Technol 48:12775-12782. https://doi.org/10.1021/es504050g

Fiordelisi A, Piscitelli P, Trimarco B, Coscioni E, Iaccarino G, Sorriento D (2017) The mechanisms of air pollution and particulate matter in cardiovascular diseases. Heart Fail Rev 22:337-347. https://doi.org/ 10.1007/s10741-017-9606-7

Gauderman WJ, Avol E, Gilliland F, Vora H, Thomas D, Berhane K, McConnell R, Kuenzli N, Lurmann F, Rappaport E, Margolis H, Bates D, Peters J (2004) The effect of air pollution on lung development from 10 to 18 years of age. N Engl J Med 351:1057-1067. https://doi.org/10.1056/NEJMoa040610 
Golokhvast KS, Chernyshev VV, Chaika VV, Ugay SM, Zelinskaya EV, Tsatsakis AM, Karakitsios SP, Sarigiannis DA (2015) Sizesegregated emissions and metal content of vehicle-emitted particles as a function of mileage: implications to population exposure. Environ Res 142:479-485. https://doi.org/10.1016/j.envres.2015. 07.018

Gustafsson M, Blomqvist G, Gudmundsson A, Dahl A, Swietlicki E, Bohgard M, Lindbom J, Ljungman A (2008) Properties and toxicological effects of particles from the interaction between tyres, road pavement and winter traction material. Sci Total Environ 393:226240. https://doi.org/10.1016/j.scitotenv.2007.12.030

IVL Swedish Environmental Research Institute (2016) (in Swedish) Urbanmätnätet- 30 års mätningar av luftkvalitet (translation: The Urban network - 30 years of air quality measurements). https:// www.ivl.se/download/18.4a88670a1596305e782220a/ 1488285806997/C230.pdf. Accessed 20th February 2019

Karlsson H, Lindbom J, Ghafouri B, Lindahl M, Tagesson C, Gustafsson M, Ljungman A (2011) Wear particles from studded tires and granite pavement induce pro-inflammatory alterations in human monocytederived macrophages: a proteomic study. Chem Res Toxicol 24:4553. https://doi.org/10.1021/tx100281f

Levels JH, Geurts P, Karlsson H, Marée R, Ljunggren S, Fornander L, Wehenkel L, Lindahl M, Stroes ES, Kuivenhoven JA, Meijers JC (2011) High-density lipoprotein proteome dynamics in human endotoxemia. Proteome Sci 9:34. https://doi.org/10.1186/14775956-9-34

Liebers V, Raulf-Heimsoth M, Brüning T (2008) Health effects due to endotoxin inhalation (review). Arch Toxicol 82:203-210. https:// doi.org/10.1007/s00204-008-0290-1

Lindbom J, Gustafsson M, Blomqvist G, Dahl A, Gudmundsson A, Swietlicki E, Ljungman AG (2006) Exposure to wear particles generated from studded tires and pavement induces inflammatory cytokine release from human macrophages. Chem Res Toxicol 19:521530. https://doi.org/10.1021/tx0503101

Lindbom J, Gustafsson M, Blomqvist G, Dahl A, Gudmundsson A, Swietlicki E, Ljungman AG (2007) Wear particles generated from studded tires and pavement induces inflammatory reactions in mouse macrophage cells. Chem Res Toxicol 20:937-946. https:// doi.org/10.1021/tx700018z

Liu H, Rönkkö T, Keskinen J (2013) Impact of vehicle development and fuel quality on exhaust nanoparticle emissions of traffic. Environ Sci Technol 47:8091-8092. https://doi.org/10.1021/es401805r

Nosratabadi AR, Graff P, Karlsson H, Ljungman AG, Leandersson P (2019) Use of TEOM monitors for continuous long-term sampling of ambient particles for analysis of constituents and biological effects. Air Qual Atmos Health 12:161-171. https://oi.org/10. 1007/s11869-018-0638-5

O'Connor GT, Neas L, Vaughn B, Kattan M, Mitchell H, Crain EF, Evans R 3rd, Gruchalla R, Morgan W, Stout J, Adams GK, Lippmann M (2008) Acute respiratory health effects of air pollution on children with asthma in US inner cities. J Allergy Clin Immunol 121:11331139. https://doi.org/10.1016/j.jaci.2008.02.020

Patashnick H, Rupprecht EG (1991) Continuous PM-10 measurements using the tapered element oscillating microbalance. J Air Waste Manage Assoc 41:1079-1083. https://doi.org/10.1080/10473289. 1991.10466903

Pope CA, Ezzati M, Cannon JB, Allen RT, Jerrett M, Burnett RT (2018) Mortality risk and PM2.5 air pollution in the USA: an analysis of a national prospective cohort. Air Qual Atmos Health 11:245-252. https://doi.org/10.1007/s11869-017-0535-3

Ristovski ZD, Miljevic B, Surawski NC, Morawska L, Fong KM, Goh F, Yang IA (2012) Respiratory health effects of diesel particulate matter. Respirology 17:201-212. https://doi.org/10.1111/j.1440-1843. 2011.02109.x

Rylander R (2002) Endotoxin in the environment-exposure and effects. J Endotoxin Res 8:241-252. https://doi.org/10.1177/ 09680519020080040101

Steenhof M, Gosens I, Strak M, Godri KJ, Hoek G, Cassee FR, Mudway IS, Kelly FJ, Harrison RM, Lebret E, Brunekreef B, Janssen NA, Pieters RH (2011) In vitro toxicity of particulate matter (PM) collected at different sites in the Netherlands is associated with PM composition, size fraction and oxidative potential-the RAPTES project. Part Fibre Toxicol 8:26. https://doi.org/10.1186/1743-8977-826

Stockfelt L, Andersson EM, Molnár P, Gidhagen L, Segersson D, Rosengren A, Barregard L, Sallsten G (2017) Long-term effects of total and source-specific particulate air pollution on incident cardiovascular disease in Gothenburg, Sweden. Environ Res 158:61-71. https://doi.org/10.1016/j.envres.2017.05.036

Tursic J, Radic H, Kovacevic M, Veber M (2008) Determination of selected trace elements in airborne aerosol particles using different sample preparation. Arh Hig Rada Toksikol 59:111-116. https:// doi.org/10.2478/10004-1254-59-2008-1872

Xing YF, Xu YH, Shi MH, Lian YX (2016) The impact of PM2.5 on the human respiratory system. J Thorac Dis 8:E69-E74. https://doi.org/ 10.3978/j.issn.2072-1439.2016.01.19

Publisher's note Springer Nature remains neutral with regard to jurisdictional claims in published maps and institutional affiliations. 